\title{
Research Paper: Evaluation of Mindfulness-Based Cognitive Therapy on the Quality of Life and Mental Health of Mothers of Deaf Children
}

\author{
Mehran Soleymani ${ }^{*}$, Golnaz Jabari ${ }^{2}$
}

1. Assistant Professor, Department of Psychology, Faculty of Education and Psychology, Azarbaijan Shahid Madani University, Tabriz, Iran.

2. MA, Department of Psychology, Faculty of Education and Psychology, Azarbaijan Shahid Madani University, Tabriz, Iran.

\begin{tabular}{l|l}
$\begin{array}{c}\text { Use yourdevice toscan } \\
\text { and read the article online }\end{array}$ \\
Citation: Soleymani M, Jabari G. Evaluation of Mindfulness-Based Cognitive Therapy on the Quality of Life and Mental Health of \\
Mothers of Deaf Children. Journal of Modern Rehabilitation. 2017; 11(1):13-22. https://doi.org/10.18869/nirp.jmr.11.1.13
\end{tabular}

Article info:

Received: 14 Jul. 2016

Accepted: 05 Nov. 2016

Keywords:

Mental health, Quality of life, Mindfulness, Cognitive therapy, Deaf children

\section{A B S T RACT}

Introduction: Family is a social system and the most important unit of human social life. In every community, retarded children are born, and their needs should be considered to prevent negative consequences on their families and improve their quality of life. Mindfulness-based interventions are considered as the third generation or third wave of cognitive-behavioral therapy. The present study aimed to investigate the effect of mindfulness-based cognitive therapy on the quality of life and mental health of mothers with deaf children.

Materials and Methods: Mothers of 24 deaf children were selected by convenience sampling method from special schools in Kermanshah and were assigned randomly to experimental $(n=12)$ and control group $(n=12)$. The experiment group received 8 sessions of mindfulness training, but the control group received no intervention. Both groups had completed short form questionnaire of the Minnesota Multiphasic Personality Inventory and the World Health Organization quality of Life questionnaire before and after the intervention. For testing the research hypotheses, multivariate analysis of covariance was used.

Results: Analysis of the results showed that mindfulness-based practices have significant $(\mathrm{P}<0.05)$ positive impact on the quality of life and its components (physical health, social health, environmental health) and on mental health of mothers with deaf children which these findings are consistent with previous research studies.

Conclusion: Because, mindfulness-based cognitive therapy improves mental health and quality of life, it is a suitable therapy to prevent problems of families with exceptional children.

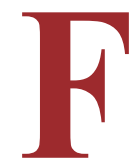

\section{Introduction}

amily is regarded as one of the main factors affecting the behavior of an individ- ual. The family environment is the first and most durable factor affecting people's personality development. Moreover, children inherit and learn many characteristics from their parents and other members of the soci-

* Corresponding Author:

Mehran Soleymani, PhD

Address: Department of Psychology, Faculty of Education and Psychology, Azarbaijan Shahid Madani University, Tabriz, Iran.

Tel: +98 (914) 3632650

E-mail: msoleymani21@yahoo.com 
ety. Parents are the main facilitator of growth and development of children. Parental influence on children goes beyond hereditary aspects; they familiarize and prepare children to community life and society culture. Family's social status, economic status, thoughts and ideas, customs, aspirations, values and their education level have a significant influence on children's behavior [1].

Birth and presence of children with hearing impairment may bring unique and difficult challenges on to the family whose emotions would be disappointment, sadness, depression, disbelief, anger, helplessness, guilt, shame and humiliation. In this regard, family members may show different behaviors such as aggression, withdrawal, or social rejection [2]. Although, all family members are hurt and their functions disrupted, mothers may experience more psychological problems because of the traditional caring care of children [3]

According to the reports of University of Social Welfare, about $10 \%$ of Iran population are disabled of which $20 \%$ have physical disabilities [4]. This percentage is huge and their problems affect all society members. If their problems remain unsolved, all family members, especially mothers may develop mental disorders and consequently enormous treatment costs that will be imposed on the society. However, in families with deaf or other physically retarded children, one of the main issues is the quality of life of parents and other family members. In many cases, the care of children with disabilities may improve their quality of life but other family members, especially mothers may suffer from losing their quality of life [5].

Quality of life is a broad concept, including mental health which is beyond physical health and involves the feeling of being healthy, satisfied, and self-worth. It is an abstract and complicated concept with various aspects addressing personal fulfillment and self-esteem [6]. There are different therapies, including pharmacotherapy and psychotherapy for providing mental health and improving quality of life for people at risk. Of therapies which focuses on the mind and mental awareness is Mindfulness-Based Cognitive Therapy (MBCT). Historically, mindfulness is a modern movement, but rooted in ancient Buddhist culture, that is clinically adapted by Kabat Zinn [7]. The practice of mindfulness involves being aware of one's moment-to-moment subjective conscious experience from a first-person perspective [8].

MBCT is a collection of strategies focusing on catching all incoming thoughts and emotions and accepting them, but not attaching or reacting to them [9]. Another research [10] reported that $\mathrm{MBCT}$ can be as effective as the new cognitive-behavioral therapies on decreasing depressive symptoms and relapse in patients with major depression. Six months follow-up showed that this treatment is more effective in preventing relapse than medication treatment. Researchers investigated the effect of MBCT on the quality of life of depressed patients [11]. Results showed that MBCT enhances the quality of life and reduces depression. Previous research studies have revealed that a combination of cognitive behavioral therapy with mindfulness-based approaches may be more effective than current treatments for depressed patients referred to counseling centers of several universities in Tehran [12].

Mindfulness is also able to reduce the negative automatic thoughts, dysfunctional attitudes, symptoms of depression and anxiety, rumination, frequency of depression symptoms, and duration of medication of these patients. In addition, it increases the medication adherence of the patient and social performance. According to the systematic review by Strauss, Bond and Cavanag, evidence supports the use of mindfulness programs in alleviating symptoms of a variety of mental and physical problems [13]. Other reviews report similar findings about the effectiveness of MBCT on mental health and well-being [14-17]. Moreover, other researchers suggest that mindfulness, i.e. the practice of focusing on your breath and thoughts, has gained popularity in the last few years. It can be practiced alone or with a guide (digital or human). It provides an opportunity for self-examination and a wholesome solution like a quiet port in the storm [18].

To our knowledge, no research has ever been conducted on the effectiveness of MBCT on mothers with deaf children in Iran. This study aimed to evaluate the effect of MBCT intervention on the quality of life and mental health in mothers with deaf children. We assessed this effect with respect to quality of life and mental health. We hypothesized that changes in two variables would be mediated by psychological flexibility and mindfulness.

Although proper attention has been reportedly paid to the problems of families with deaf children, mental health and quality of life in parents and their coping with psychological problems caused by the birth of deaf children and comparison between them and mothers of normal children have been overlooked. The results of this study can be used by parents and educators to pay more attention to the parents' feelings and needs and to improve their quality of life and self-actualization. Moreover, the results of this research can be used by the psychology students and researchers in this field. 
Fulfillment of people's health requirements is the basic issue of each society and comprises three aspects: physical, mental and social. If mental health is not duly considered then psychological and behavioral problems will ensue and their consequences will impose irreversible adverse effects on personal, family, social, human, political, economic and cultural aspects [19]. This study aimed to evaluate the effectiveness of MBCT on mental health and quality of life of mothers of deaf children in the city of Kermanshah.

\section{Materials and Methods}

\section{Research design}

This is a quasi-experimental study using Pre-test-posttest with a control group. The study population consisted of all mothers of deaf children studying in school of deaf children in Kermanshah. The study sample consisted of 24 mothers of deaf children who were selected by convenience sampling method and then randomly divided into experimental $(n=12)$ and control $(n=12)$ groups. Then the experimental group participated in 8 weekly sessions of MBCT for two months held by the researcher. The control group knew that they could start the training after the experimental group completed the intervention. Finally, to comply ethical principles, the MBCT course was held for the control group, too.

Inclusion criteria were as follows: Having children with hearing impairment; Education level up to the eighth grade; and Their children must study in exceptional school of the deaf children. Exclusion criteria were as follows: Receiving psychological or pharmacological treatment for mental complaints within the last three months; and Having other severe mental or social problems that were under treatment which likely to interfere with participation in intervention.

\section{Measures}

Questionnaire of quality of life (short form) of World Health Organization (WHOQOL-BREF): WHOQOL project started in 1991. It aimed to develop an international cross-culturally comparable quality of life instrument, which assesses the individuals' perceptions in the context of their culture, value systems, personal goals, standards and concerns. The project was developed collaboratively in a number of centers worldwide, and has been widely field-tested. The WHOQOL-BREF, a short version of the original instrument, is more convenient to use in large research studies or clinical trials. It measures four aspects of physical health, mental health, social re- lations, and environmental health with 24 items (questions of each aspect were 7, 6, 3 and 8, respectively).

The first two questions do not belong to any areas of health and quality of life in general. So, there are 26 questions. First, a raw score is obtained for each subscale and then standardized between 0 and 100. A higher score indicates higher quality of life. Nejat and colleagues studied Persian version of the questionnaire and confirmed its validity. To test its reliability, the Cronbach $\alpha$ was used. The Cronbach $\alpha$ value for the whole questionnaire is 0.88 and for each subscale is higher than 0.7 [20]. To calculate its reliability, the correlation between total score and each item was determined so the range of correlation was between 0.45 to 0.83 that was significant at 0.01 level $[21,22]$.

Mental health test of Minnesota Multiphasic Personality Inventory (MMPI, short form version): This self-report test is one of the popular measures among neuropsychologists [23-25]. The original version was published by Hathaway and McKinley in 1940. The scales were developed empirically. Items of each scale were chosen on the basis of their ability to discriminate between clinical and normal groups. Thus, these scales tend to be heterogeneous in nature. MMPI-2 with 567 items can be prohibitive. The original validity scales (L, F, K) and clinical scales are graded from the first 370 items, but it is better to complete the entire test so that all validity indicators, content scales, and supplementary scales can be scored [26]. However, a shortened version consisting of the first 180 items has been proposed (MMPI-2-180) [26]. Fathi conducted a research on high school students and calculate general reliability by Kuder-Richardson and Cronbach $\alpha$ as 0.91 that is significant at 0.001 . MBCT sessions were held during 8 sessions as presented in Table 1.

\section{Procedure}

Participants were recruited in a school meeting with mothers of deaf children. In the meeting, the target group became familiar with the objectives of the research. Then, they completed written informed consent forms. After selecting participants they were randomly assigned into experimental and control groups, and psychological wellbeing questionnaire was administered to both groups. Intervention program was trained during 8 weekly sessions based on Khazen et al. MBCT (Table 1) [27].

\section{Data analysis}

Descriptive statistics including mean and standard deviation of research variables as well as ensuring about statisti- 
cal pre-assumptions normality (by Kolmogorov-Smirnov test) were calculated for each variable. Also, inferential statistics including MANCOVA and analysis of covariance were performed. SPSS 19 was used for analysis.

\section{Results}

Findings of descriptive statistics of research variables for both experimental and control groups in the Pre-test and post-test are presented in Tables 2 and 3. According to this table, the average scores of the two groups were almost equal in Pre-test but in post-test, the average scores of the experimental group were more than those of the control group. According to Table 3, the average scores of the two groups were pretty equal in Pre-test but in post-test, the scores of the experimental group were less than those of the control group. It means that experimental group in post-test got scores less than control group in subscales of psychosocial deviation, hysteria, mental fatigue and depression because, lower scores in these subscales show higher mental health.

\section{The main hypothesis}

MBCT has positive effects on mental health and quality of life of mothers with deaf children in Kermanshah. In order to test this hypothesis by controlling Pre-test effects on post-test scores, we divided it into sub-hypothesis and then multivariate ANCOVA was used. Multivariate analysis of covariance is presented for each sub-hypothesis. Box' $M$ test for homogeneity of variance-covariance and Levene's test for equality of variances were conducted and results are shown in Tables 4, 5 and 6. Box' $M$ test evaluates whether the data questioned matrix homogeneity of variance-covariance. The significance level showed that homogeneity of variance-covariance was met.

According to Table 7, after adjusting Pre-test scores, there was a significant effect of factor between subjects with effect size (0.179). In other words, the study hypothesis "MBCT effects on the mental health of mothers of deaf children" is approved. Table 8 shows

Table 1. The content of intervention sessions

Session Time, Min
Content

1 functioning of the mind and its role in the production of thoughts, behavior and how to control those (60 minutes); Familiarity with relaxation and attention to the present moment without judgment and current affairs (30 minutes); Providing weekly home assignments and answers to questions (30 minutes).

Checking homework, ideas and new experiences of the previous week, answering to questions (30 minutes); Basic familiarity with cognitive therapy and its difference with other treatment methods. Introduction to mindfulness program (90 minutes); Offering weekly home assignments and answers to questions (30 minutes).

(30 minutes).

Checking homework, ideas and new experiences of the previous week. Answering the questions (30 minutes); Holding mindfulness training and practices of concentrated attention toward breathing without judgment (60 minutes). Providing weekly home assignments and answers to questions (30 minutes).

Checking homework, ideas and new experiences of the previous week. Answering the questions (30 min135 utes); Again, practicing breathing exercise (15 minutes); Training and practicing body checking techniques (60 minutes); Provide weekly home assignments and answers to questions (30 minutes).

\begin{tabular}{|c|c|c|}
\hline 5 & 150 & $\begin{array}{l}\text { Checking homework, ideas and new experiences of the previous week. Responding to the questions, } \\
\text { practice breathing and body checking ( } 60 \text { minutes); Learning and practicing mindful seeing techniques (60 } \\
\text { minutes); Offer weekly home assignments and answers to questions ( } 30 \text { minutes). }\end{array}$ \\
\hline 6 & 150 & $\begin{array}{l}\text { Checking homework, ideas and new experiences of the previous week, answering to questions, practice } \\
\text { breathing and body checks and mindful observation ( } 60 \text { minutes); Learning and practicing techniques of } \\
\text { mindful hearing ( } 60 \text { minutes); Offering weekly assignments and answer the questions ( } 30 \text { minutes). }\end{array}$ \\
\hline 7 & 150 & $\begin{array}{l}\text { Checking homework, ideas and new experiences of the previous week. Responding to questions, practice } \\
\text { of body checking, mindful watching and listening ( } 60 \text { minutes); Training and exercising conscious control } \\
\text { without judgment ( } 60 \text { minutes); Offering weekly home assignments and answers to questions ( } 30 \text { minutes). }\end{array}$ \\
\hline 8 & 150 & $\begin{array}{l}\text { Checking homework attitudes and total experiences of mothers. Answering the questions (60 minutes); } \\
\text { Reviewing and evaluating views and ideas of participants and their general comment of sessions and sum- } \\
\text { marize whole contents ( } 90 \text { minutes). }\end{array}$ \\
\hline
\end{tabular}


Table 2. Descriptive statistics of aspects of quality of life

\begin{tabular}{|c|c|c|c|c|c|c|}
\hline \multirow{2}{*}{ Variable } & \multirow{2}{*}{ Number } & \multirow{2}{*}{ Group } & \multicolumn{2}{|c|}{ Pre-Test } & \multicolumn{2}{|c|}{ Post-Test } \\
\hline & & & Mean & SD & Mean & SD \\
\hline \multirow{3}{*}{\multicolumn{2}{|c|}{ Social health }} & Experimental & 3.3583 & 0.63883 & 3.5667 & 0.80151 \\
\hline & & & & & & \\
\hline & & Control & 2.6917 & 0.56320 & 2.8000 & 0.81240 \\
\hline \multirow{3}{*}{\multicolumn{2}{|c|}{ Physical health }} & Experimental & 3.2750 & 0.50655 & 3.5000 & 0.53767 \\
\hline & & & & & & \\
\hline & & Control & 3.1500 & 0.65713 & 3.0750 & 0.58949 \\
\hline \multirow{3}{*}{\multicolumn{2}{|c|}{ Mental health }} & Experimental & 2.8733 & 0.74691 & 03.4333 & 0.72530 \\
\hline & & & & & & \\
\hline & & Control & 3.1583 & 0.81849 & 0.1583 & 0.79253 \\
\hline \multirow{3}{*}{\multicolumn{2}{|c|}{ Environmental health }} & Experimental & 2.8250 & 0.61515 & 3.0500 & 0.58075 \\
\hline & & & & & & \\
\hline & & Control & 2.6333 & 0.53654 & 2.6417 & 0.52303 \\
\hline \multirow{3}{*}{\multicolumn{2}{|c|}{ Total score of quality of life }} & Experimental & 12.2417 & 1.92186 & 13.5500 & 2.26495 \\
\hline & & & & & & \\
\hline & & Control & 11.6333 & 2.47912 & 11.6750 & 2.62614 \\
\hline
\end{tabular}

$J \mathrm{MR}$

that the F level in subscales 1,3 and 4 is significant. That intervention had effectiveness on the above mentioned subscales in the experimental group. The last column shows the effect size in each case. The size of the effects of the independent variables in subscale 3 is 0.198 that is more than the other subscales.

\section{Discussion}

To the best of our knowledge, this is the first study to evaluate the efficacy of MBCT in mothers of deaf children in Iran. Intervention was expected to improve depression symptoms in mothers compared to the control group. For this reason, we ran an experimental, random-

Table 3. Descriptive statistics of mental health

\begin{tabular}{|c|c|c|c|c|c|c|}
\hline \multirow{2}{*}{ Variable } & \multirow{2}{*}{ Number } & \multirow{2}{*}{ Group } & \multicolumn{2}{|c|}{ Pre-Test } & \multicolumn{2}{|c|}{ Post-Test } \\
\hline & & & Mean & SD & Mean & SD \\
\hline \multirow{3}{*}{ Depression } & 12 & Experimental & 6.2500 & 2.92715 & 4.1667 & 2.44330 \\
\hline & & & & & & \\
\hline & 12 & Control & 5.3333 & 3.96194 & 5.5000 & 4.14510 \\
\hline \multirow{3}{*}{ Mental fatigue } & 12 & Experimental & 9.3333 & 4.81160 & 6.4167 & 5.23030 \\
\hline & & & & & & \\
\hline & 12 & Control & 8.2500 & 3.10791 & 8.9167 & 3.80092 \\
\hline \multirow{3}{*}{ Psychosocial deviation } & 12 & Experimental & 12.6667 & 3.74975 & 10.5000 & 3.14787 \\
\hline & & & & & & \\
\hline & 12 & Control & 9.9167 & 4.90748 & 10.000 & 4.89898 \\
\hline \multirow{3}{*}{ Hysteria } & 12 & Experimental & 6.8333 & 2.08167 & 4.2500 & 3.13702 \\
\hline & & & & & & \\
\hline & 12 & Control & 6.2500 & 3.25087 & 5.9167 & 3.14677 \\
\hline \multirow{3}{*}{ Total score of mental health } & 12 & Experimental & 71.4167 & 23.29830 & 51.4167 & 26.10280 \\
\hline & & & & & & \\
\hline & 12 & Control & 65.8333 & 26.31233 & 67.8333 & 28.03839 \\
\hline
\end{tabular}


Table 4. Results of Box's M test

\begin{tabular}{ccccc}
\hline Box's M & F & df1 & df2 & Sig. \\
\hline 6.141 & 1.845 & 3 & 87120 & 0.136
\end{tabular}

Table 5. Results of pre-assumption of Levene's for equality of variances between groups in mental health

\begin{tabular}{cccc}
\hline Sig. & df1 & df2 & F \\
\hline 0.3930 & 22 & 1 & 0.760
\end{tabular}

$J M R$

Table 6. Results of pre-assumption of Levene's for equality of variances between groups with regard to the quality of life

\begin{tabular}{cccc}
\hline Sig. & df1 & df2 & F \\
\hline 0.341 & 22 & 1 & 0.949
\end{tabular}

Table 7. Results of MANCOVA analysis of MBCT effects on mental health

\begin{tabular}{cccccccc}
\hline Variable & Reference & SS & df & Mean & F & P & R Square \\
\hline & Modified & 61.241 & 2 & 30.620 & 7.039 & 0.005 & 0.401 \\
& Within & 8.31 & 1 & 8.313 & 1.911 & 0.181 & 0.083 \\
& Pre-test & 44.422 & 1 & 44.422 & 10.212 & 0.004 & 0.327 \\
$\begin{array}{l}\text { Mental } \\
\text { health }\end{array}$ & Group & 19.1879 & 1 & 19.1879 & 4.570 & 0.004 & 0.179 \\
& Errors & 91.345 & 21 & 4.350 & & & \\
& Total & 1232.636 & 24 & & & & \\
& & & & & & \\
\hline
\end{tabular}

ized-controlled study. The results of this study suggest that MBCT increases the mental health and quality of life of mothers of deaf children. In addition, the improvement in mental health of the population who received MBCT were substantial.
The results of Sohrabi study were consistent with the results of this study [28]. Schulman and Vala reported similar findings in research on mindfulness effectiveness on depression, anxiety and panic [29, 30]. In the last few years, MBCT has not only been proven to be a feasible and acceptable intervention; but also effective

Table 8. Results of MANCOVA analysis of MBCT effects on quality of life

\begin{tabular}{ccccccc}
\hline Statistical Indexes & Ss & df & Ms & F & Sig. & Eta \\
Subscales & & 1 & 1.084 & 3.405 & 0.049 & 0.134 \\
\hline Physical health & 1.084 & 1 & 0.454 & 0.786 & 0.385 & 0.035 \\
Mental health & 0.454 & 1 & 3.527 & 5.416 & 0.030 & 0.198 \\
Social health & 3.527 & 1 & 1.200 & 3.776 & 0.044 & 0.140 \\
\hline Environmental health & 1.200 & & & & & \\
\hline
\end{tabular}


in reducing psychological syndromes such as anxiety and depression [31-34]. These consistent findings are based on the fact that individuals susceptible to depression or other psychological problems become distressed and return to automatic cognitive processes that can harm mental health [16].

MBCT aims at interrupting these processes and teaches the participants not to react to incoming stimuli, but instead to accept and observe them unbiased [8]. The mindfulness practice may have helped mothers become more aware of their distress, and handle them better. Baer demonstrated that by practicing mindfulness, mental health can be promoted through an improved ability to observe with acceptance and without judgment or reaction $[33,34]$.

These mindfulness practices alert the people of their automatic processes and adjust their reactions into something more than a reflection. Regarding the quality of life, the results also show that there are significant differences between the control group and the experimental group in Pre-test and post-test. These findings are consistent with findings of Fleer et al. [35] who reported effectiveness of MBCT for the treatment of seasonal affective disorder and Williams et al. [36] reported effectiveness of MBCT for preventing relapse in recurrent depression. And Sedaghati, Younesi and Sedaghati conducted a research on the effectiveness of MBCT on the quality of life in mothers of children with cerebral palsy and their findings revealed that MBCT program improved the quality of life of the participants [37].

Pots, Meulenbeek, Veehof conducted a research on the efficacy of MBCT as a public mental health intervention for adults with mild to moderate depressive symptoms [38]. They reported that MBCT seems to be effective and applicable in a natural setting. Their finding are consistent with our findings. To explain these results we can say that since rumination (of the past) and worry (about the future) are considered as threatening factors for mental health and quality of life in susceptible people [39], autonomous mind may be deviated by imagination and judgment about past, present and future events as well as emerging cognitive errors. It is thought that by controlling two factors i.e. rumination and worry, we can prevent or control problems of mental health and improve quality of life [40].

To last longer the effects of intervention, some studies show that the effects of mindfulness are more durable and effective than other methods $[8,33]$. It seems that this therapy can enhance quality of life [40]. The effec- tiveness of mindfulness practices can be explained by an increase in psychological flexibility of its practicers, because participants have gained additional adaptive emotion regulation skills in response to negative affect-producing stressors. Thus, considering the effectiveness of this techniques in the treatment of depression and quality of life, this method is recommended. The present study may contribute to evidence-based knowledge concerning the efficacy of mindfulness training to support mothers in benefitting from high quality of life and mental health in raising their deaf children.

This study has some limitations. Some relevant variables to the study like resiliency and social adjustment have not been investigated. Also, the research was done in Kermanshah City and cannot be generalized to other communities. Because this research has been carried out mainly on the mothers of children who are deaf so it cannot be generalized to other family members. In addition, follow up study was not conducted. By considering these limitations it is suggested that future studies be focused on other groups, including mothers of children with mental retardation and even other family members, also other variables such as age, education, income level, urban or rural residency and social adjustment will be considered in similar research studies. Finally, a longer follow-up (e.g. for one year) is recommended for future research studies in this topic, too.

\section{Acknowledgements}

We thanks mothers and children who participate in this research. This research did not receive any specific grant from funding agencies in the public, commercial, or notfor-profit sectors.

\section{Conflict of Interest}

The authors declared no conflicts of interest.

\section{References}

[1] Shariatmadari A. [Education psychology (Persian)]. Tehran: Amir Kabir Publication; 2013.

[2] Ghasempoor A, Akbari E, Taghipoor M, Azimi Z, Refaghat E. [Comparison of psychological well-being and coping styles in mothers of deaf and normally-hearing children (Persian)]. Audiology. 2012; 21(4):51-59.

[3] Mollie N. Family problems of deaf children. SEDA Research Magazine. 2010; 28:1-11. 
[4] Ghafari Gh, Karimi A, Nozari H. [Trend study of quality of life in Iran (Persian)]. Quarterly of Social Studies and research in Iran. 2013; 1(3):107-134. doi: 10.22059/jisr.2013.36564

[5] Kakavand A. [Learning disabilities (diagnosis and strategies) (Persian)]. Tehran: Sarafraz Publication; 2006.

[6] Ranjbar FH, Kakavand AR, Borjali A, Barmas H. [Resilience and quality of life of mothers with mentally retarded children (Persian)]. Quarterly Journal of Health and Psychology. 2011; 1(1):77-87.

[7] Falkenström F. Studying mindfulness in experienced meditators: A quasi experimental approach. Personality and Individual Differences. 2010; 48(3):305-10. doi: 10.1016/j. paid.2009.10.022

[8] Kabat Zinn J, Hanh TN. Full catastrophe living: Using the wisdom of your body and mind to face stress, pain, and illness. Illinois: Delta Publishing; 2009.

[9] Hofmann SG, Sawyer AT, Fang A. The empirical status of the "New Wave" of cognitive behavioral therapy. Psychiatric Clinics of North America. 2010; 33(3):701-10. doi: 10.1016/j. psc.2010.04.006

[10] Mohamadkhani P, Dobson K, Hosseini Ghafari F, Poshtmashhadi M, Saijadi S. Additional psychiatric symptoms and response to treatment in a sample of Iranian recovered depressed patients. Journal of Practice in Clinical Psychology. 2013; 1(1):3-7

[11] Kaviani H, Hatami N, Javaheri F. The impact of Mindfulness-Based Cognitive Therapy (MBCT) on mental health and quality of life in a sub-clinically depressed population. Archives of Psychiatry and Psychotherapy. 2012; 1:21-8.

[12] Khodabakhsh Pirkalani R, Rahim Jamarouni H. [Effectiveness of mixed cognitive-behaviorial therapy and mindfulness based stressreduction in treating a case of generalized anxiety disorder (Persian)]. Clinical Psychology Studies. 2014 4(13):121-47.

[13] Gotink RA, Chu P, Busschbach JJV, Benson H, Fricchione GL, Hunink MGM. Standardised mindfulness based interventions in healthcare: An overview of systematic reviews and meta analyses of RCTs. PLOS ONE. 2015; 10(4):e0124344. doi: 10.1371/journal.pone.0124344

[14] Sharma M, Rush SE. Mindfulness based stress reduction as a stress management intervention for healthy individuals. Journal of Evidence Based Complementary \& Alternative Medicine. 2014; 19(4):271-86. doi: 10.1177/2156587214543143

[15] Garland EL, Froeliger B, Howard MO. Mindfulness training targets neurocognitive mechanisms of addiction at the attention appraisal emotion interface. Frontiers in Psychiatry. 2014; 4. doi: 10.3389/fpsyt.2013.00173

[16] Sequeira S. Foreword to advances in meditation research: Neuroscience and clinical applications. Annals of the New York Academy of Sciences. 2014; 1307(1):v-vi. doi: 10.1111/ nyas.12305

[17] Khoury B, Sharma M, Rush SE, Fournier C. Mindfulnessbased stress reduction for healthy individuals: A meta-analysis. Journal of Psychosomatic Research. 2015; 78(6):519-28. doi: 10.1016/j.jpsychores.2015.03.009
[18] Dobkin PL, Hassed CS. Why teach mindfulness to clinicians. Mindful Medical Practitioners. 2016; 1-8. doi: 10.1007/978-3-319-31066-4_1

[19] Magee L, Scerri A, James P. Measuring social sustainability: A community centred approach. Applied Research in Quality of Life. 2012; 7(3):239-61. doi: 10.1007/s11482-012-9166-x

[20] Nejat S, Montazeri A, Holakouie Naieni K, Mohammad K, Majdzadeh S. [The World Health Organization quality of Life (WHOQOL-BREF) questionnaire: Translation and validation study of the Iranian version (Persian)]. Public Health and Institute of Public Health Research. 2006; 4(4):1-12.

[21] Nasiri HA, Hashemi LV, Hosseini SM. Use of WHOQOLBREF to assess students' quality of life. Mental Health Seminars. 2004; 1:365-8.

[22] Usefy AR, Ghassemi GR, Sarrafzadegan N, Mallik S, Baghaei AM, Rabiei K. Psychometric properties of the WHOQOL-BREF in an Iranian adult sample. Community Mental Health Journal. 2010; 46(2):139-47. doi: 10.1007/s10597-0099282-8

[23] Camara WJ, Nathan JS, Puente AE. Psychological test usage: Implications in professional psychology. Professional Psychology: Research and Practice. 2000; 31(2):141-54. doi: 10.1037/0735-7028.31.2.141

[24] Rabin L, Barr W, Burton L. Assessment practices of clinical neuropsychologists in the United States and Canada: A survey of INS, NAN, and APA Division 40 members. Archives of Clinical Neuropsychology. 2005; 20(1):33-65. doi: 10.1016/j. acn.2004.02.005

[25] Butcher JN. Minnesota multiphasic personality inventory (MMPI). International Encyclopedia of the Social \& Behavioral Sciences. 2001; 9891-4. doi: 10.1016/b0-08-0430767/01294-8

[26] Dahlstrom WG, Archer RP. A shortened version of the MMPI-2. Assessment. 2000; 7(2):131-41. doi $10.1177 / 107319110000700204$

[27] Khazan IZ. The clinical handbook of biofeedback: A step by step guide for training and practice with mindfulness. New Jersey: John Wiley \& Sons; 2013. doi: 10.1002/9781118485309

[28] Sohrabi SF, Jafari FS, Zareii S, Eskandari H. [The effectiveness of cognitive-based cognitive therapy on predominating disorder: A case study (Persian)]. Journal of Clinical Psychology. 2002; 4(4):31-39.

[29] Seligman ME, Schulman P, Tryon AM. Group prevention of depression and anxiety symptoms. Behaviour Research and Therapy. 2007; 45(6):1111-26. doi: 10.1016/j.brat.2006.09.010

[30] Vala M, Razmane R, Rambod K, Nasli Esfahani E, Ghodsi Ghasem Abadi R. [Mindfulness-based stress reduction group training on depression, anxiety, stress, self-confidence and hemoglobin A1C in young women with type 2 diabetes (Persian)]. Iranian Journal of Endocrinology \& Metabolism. 2016; 17(5):382-390.

[31] Cavanagh K, Strauss C, Forder L, Jones F. Can mindfulness and acceptance be learnt by self-help: A systematic review and meta analysis of mindfulness and acceptance based self-help interventions. Clinical Psychology Review. 2014; 34(2):118-29. doi: 10.1016/j.cpr.2014.01.001 
[32] Gu J, Strauss C, Bond R, Cavanagh K. How do mindfulness based cognitive therapy and mindfulness based stress reduction improve mental health and wellbeing? A systematic review and meta analysis of mediation studies. Clinical Psychology Review. 2015; 37:1-12. doi: 10.1016/j.cpr.2015.01.006

[33] Felder JN, Dimidjian S, Segal Z. Collaboration in mindfulness based cognitive therapy. Journal of Clinical Psychology. 2012; 68(2):179-86. doi: 10.1002/jclp.21832

[34] Baer RA. Mindfulness training as a clinical intervention: A conceptual and empirical review. Clinical Psychology: Science and Practice. 2003; 10(2):125-43. doi: 10.1093/clipsy/ bpg015

[35] Fleer J, Schroevers M, Panjer V, Geerts E, Meesters Y Mindfulness based cognitive therapy for seasonal affective disorder: A pilot study. Journal of Affective Disorders. 2014; 168:205-9. doi: 10.1016/j.jad.2014.07.003

[36] Williams JMG, Crane C, Barnhofer T, Brennan K, Duggan DS, Fennell MJV, et al. Mindfulness based cognitive therapy for preventing relapse in recurrent depression: A randomized dismantling trial. Journal of Consulting and Clinical Psychology. 2014; 82(2):275-86. doi: 10.1037/a0035036

[37] De Vibe M. Mindfulness based stress reduction (MBSR) for improving health, quality of life, and social functioning in adults. The Campbell Collaboration; 2012; doi: 10.4073/ csr.2012.3

[38] Pots WTM, Meulenbeek PAM, Veehof MM, Klungers J Bohlmeijer ET. The efficacy of mindfulness based cognitive therapy as a public mental health intervention for adults with mild to moderate depressive symptomatology: A randomized controlled trial. PLoS ONE. 2014; 9(10):e109789. doi: 10.1371/journal.pone.0109789

[39] Chiesa A, Anselmi R, Serretti A. Psychological mechanisms of mindfulness based interventions. Holistic Nursing Practice. 2014; 28(2):124-48. doi: 10.1097/hnp.0000000000000017

[40] Ryff CD, Friedman EM, Morozink JA, Tsenkova V. Psychological resilience in adulthood and later life: Implications for health. Annual Review of Gerontology and Geriatrics. 2012; 32(1):73-92. doi: 10.1891/0198-8794.32.73 
